\title{
Creativity and Innovation Skills in University STEM Education: The CHET Project Approach
}

César García-Aranda, Agustin Molina-García, Ma Carmen Morillo, Sandra MartínezCuevas, Encarnación Rodríguez, Javier Pérez, Jorge Rodríguez-Chueca, Yago Torroja, Manuel Rodríguez, María González, F. Ismael Díaz, Emilio J. González, Ma Mar de la Fuente, Stefanos Giannakis, Isabel del Castillo, Margarita Martínez, Fernando Blasco, Pilar C. Izquierdo

Universidad Politécnica de Madrid (Madrid) Spain.

\begin{abstract}
Creativity and innovation are crucial skills to face challenges in economy, environment and social context today, especially next decade with 2030 Agenda for Sustainable Development adopted by all United Nations Member States. European Higher Education System considers STEM studies play a key role to lead the global labor market and address our economic system towards more sustainability and equality model.

Innovative educational projects developed at the Universidad Politécinca de Madrid have identified lack of students skills in creativity and innovation to apply challenge based-learning and others methodologies in classrooms.

Hovewer Higher Education institutions need a whole approach to include creativity in university curricula (graduate and postgraduate programs), at the same time, professors claim support to embebed innovative methodologies in their subjects.

CHET Project is designed as a solid strategy aimed at developing an innovative process to modernization of Higher Education System in Europe. Step by step, the project begins by defining the learning environment, then developing creativity techniques and tools, and finally validating methodologies and processes. All this supported by free access online platform.
\end{abstract}

Keywords: creativity; innovation; STEM; learning environment. 


\section{Introduction}

The importance of creativity and innovation in addressing the economic, environmental and social crises has been recognized in Europe. Recent policies call for the strengthening of Europe's innovative capacity and the development of a creative and knowledge-intensive economy and society.

De Bono (1970), in "Lateral thinking", stresses the importance of the use of creativity and innovation in the classroom, and considers these key in giving their students the skills to face and solve complex problems.

On top of that, the last decade has seen a paradigm change in the characteristics of Higher Education (HE) students, the economic and other pressures and demands of the labour market, are generating career changes or the need for additional education in later life. At the same time the age of students entering university after secondary education has been slowly decreasing. Diversity among students has also been increasing. All the above poses a challenge on HE teachers, which have to deal with students from a variety of backgrounds and skills levels.

This has generated a challenge for HE teachers to be more effective in teaching and to make teaching and learning relevant, for society, for the labour market and for the students themselves. Experiences have shown that using creativity techniques and innovation increase the problem-solving and innovative capacity of their students, while at the same time increasing their motivation (Rodriguez-Chueca et al., 2019).

This is confirmed by "Innovating Learning: Key Elements for Developing Creative Classrooms in Europe", a EU Joint Research Centre study (2012), which highlights that HE institutions need to emphasize the importance of creativity and innovation for modernising education, it also identifies as one of the main improvement areas the training and education of HE teachers.

From a job perspective, as outlined in the conclusions of the "Annual Report on Labor Flexibility and Employment" by Randstad Research (2016), STEM (Science, Technology, Engineering and Mathematics) jobs offer higher levels of productivity growth through the introduction of new technologies and innovations. To achieve this, it is necessary to convince teachers about the necessity of the renewal of teaching methodologies to further promote the competences in creative skills of students (Shernoff et al., 2017).

HE institutions an important role in this, as they have to provide their students with an education that will enable them to adapt to an increasingly globalised, competitive, diversified and complex environment (Csikszentmihalyi \& Wolfe, 2014) in which creativity, the ability to innovate, a sense of initiative, entrepreneurship and a commitment to continue learning are just as important as the specific knowledge of a given subject. Current 
educational systems do not answer the demands of the labour market for professionals with innovative, problem-solving and entrepreneurial capacities.

When teachers finish their university degrees, they have no problems with contents they have to impart; through practice they acquire the necessary skills to became good teachers; However, what they neither learn at university nor through practice are the skills that make them "innovative and creative teaching professionals".

By providing HE teachers will skills and competences to integrate creativity and innovation in their teaching activities, they will contribute to a better preparation of their students and are better placed to provide an answer to the needs of the varied classrooms (EUA, 2007). The HE institutions recognise that preparing and motivating students is key and that they are part of the solution, as their teachers are pivotal in fostering and developing students creative and innovative capacities.

\section{CHET Project background and objetives}

Since the beginning 2016-17 course, a Universidad Politécnica de Madrid (UPM, Spain) professor's team has develop successive innovative education research projects, address to engage students and improve learning process integrated innovative methodologies (Flipped classroom, Challenge-base learning, ...).

One of the most important result was students has serious difficult to apply creativity and innovative solutions in solving real problems or situation proposed during the semester. From this point of view, we worked on a desing project that would provide a whole vision of learning creativity in Higher Education. This challenge needed an more complete approach and collaboration with other european universities.

Finally a consortium group was formed with six partners, four universities: Universidad Politécnica de Madrid (Spain), University of Southern Denmark (Denmark), Vilnius Gediminas Technical University (Lithuania), Ege University (Turkey), joined together with two methodology support and technology companies: Avaca Technologies Consulting, Informatics AE (Greece) and EOLAS S.L. (Spain).

In this context the CHET (Creativity for Higher Education Teachers) project emerged, supported by Erasmus+ (Key Action 2) focusses on STEM High Education teachers. On the one hand, because the participating HE institutions indicate that it is in these type of studies where they see the take up of innovative teaching activities is slower. On the other, because Europe needs professionals trained in these subjects. Bringing about a change in the way education is approached, addressing better the needs of the labour market and the challenges of a varied classroom, will increase the attractiveness of these studies and reduce drop-out rates. In this framework, creativity definition is understood like as outcome of a process and 
has four main characteristics: originality, appropriateness, future orientation and problemsolving ability (EUA, 2007)

CHET addresses these challenges by providing STEM HE teachers, with the skills and pedagogical competences to embed innovation and creativity in their their teaching activities. To make this happen the project will develop e-learning materials and content, based upon the needs of STEM HE teachers, delivered through the CHET learning environment, which will allow them to implement learner-centred learning approaches which foment creativity and innovation among their students and provide them knowledge and insights on how to increase the interactive learning of students with teachers and peers.

Tackling a challenge which is present across European Union (EU) countries and educational systems, is only possible on a European level, through intense cooperation of relevant players. The transnationality is vital to learn from each other experiences in how different national educational systems address the issues and to detect good practices across different countries. Knowledge from different EU regions will be combined and integrated into the Intellectual Outputs. Current European landscape on implementation of creativity techniques and innovation in HE STEM studies has not been mapped, and there are no guidelines on which approaches or techniques are better suited for a specific STEM context, CHET aims to provide these.

\section{Methodology: step by step}

First, for the learning approach to be robust it needs to be based upon a set of solid findings and contrasted with the targeted learners (i.e. STEM HE teachers). Secondly, the design of the learning environment will aware easy access to a set of creativity techniques, and finally all this will be validated in practice with teachrs and students.

\subsection{Baseline studies and curricula design}

It will take as a starting point the findings from the desk research and analysis of existing activities applied among participant universities. These research results will lead to an initial list of factors that are considered as key elements for creativity and innovation in STEM HE education, such as the needs of the STEM HE teachers, the challenges for practical implementation and the sources for knowledge on the topic.

These initial results and list will be presented in a focus group approach to STEM HE teachers will be executed in 4 project countries and possibly covering more countries through the existing networks of the partners. The focus groups will provide insight into the current state of skills, knowledge and attitudes among the teachers and their institutions, allows to lay the baseline for the determination of the curriculum, which will describe the specific skills, 
knowledge and attitudes that both the STEM HE teachers and the HE institutions need to have to be able to fully embed creativity and innovation in the teaching.

As a result the overall learning approach for CHET will become evident, the overall results of the preliminary research focus groups and curriculum will be basis on which to define in detail the CHET learning approach, which consists of a description of the learning objectives; the learning process; the learning content (i.e. the curriculum) and the assessment methodology.

\subsection{Defining the learning approach}

The first activity will be the identification of those creativity techniques that are relevant for the target public, these will then be mapped against the existing materials and knowledge from the partners so as to identify those materials already existing and which can be adapted to the needs of the target public. By building upon existing materials and knowledge the consortium can include with the same effort a larger amount of techniques and experiences, thus generating a sufficient critical mass of content, within the limits of the project and its resources. The map will also identify those areas of knowledge and/or techniques for which no existing material exist (or not of sufficient quality) and thus requires new development.

The CHET learning content will cover two aspects:

- Understanding and knowledge of the specific creativity techniques, and the underlying processes of educational innovation in teaching activities.

- Understanding and knowledge on when and how to apply a particular creativity technique, depending on the learning contexts and circumstances.

The first aspect focuses on the more theoretical aspects of creativity techniques. A selected set of most relevant creativity techniques will be explored and described in more detail, based upon the recommendations from the learning approach section. Each of the identified techniques will be defined using a set of common descriptors, introducing the technique and the underlying educational innovation processes to the learner. The techniques are classified as per a defined ontology and semantics (theme, type, etc), so as to ensure their seamless integration in the app and their alignment with the app's search engine and options. The underlying materials and content related to creativity and the educational innovation processes developed and will be made available through the e-learning platform so as to allow for more profound exploration of a specific topic, aspect or technique.

For each of the selected creativity techniques the second aspect will explore for which type of learning contexts and circumstances the techniques is most effective, (e.g. size of the student group, subject, topic etc), resulting in a second level semantics and ontology. For each of the techniques, experiences, best practices and examples are mapped, and those 
considered most relevant these are described, including tips and tricks on how to implement them in practice.

\subsection{Content elaboration and CHET learning environment}

The contents for the e-learning platform consists of:

- Theoretical descriptor of the creativity technique

- Tips and tricks on the practical implementation (including references to circumstances under which it has been more effective)

- Examples (including best practices and short case studies) of their use by peer STEM HE teachers.

The e-learning platform will allow easy access to a set of creativity techniques with theory and practice (examples, best practices, tips and hints) represented in a user-friendly way, and adapted for mobile platforms (type to be determined based upon the preferences of the HE STEM teachers). The e-learning platform will provide the space for the participants to drill deeper into the skills, knowledge and attitudes identified by the research activities and developed in the content of CHET learning content, it is also the place for knowledge sharing.

The CHET e-learning platform will also include the development and implementation of the assessment methodology, based on the content of the training programme, the learning objectives and needs.

\subsection{Testing and validation}

Within this task, the most suitable pilot testing and validation methodology will be established and statistical and qualitative analysis techniques will be selected. Objectives of the pilot validation need to be clearly defined and be common to all as they are detrimental to the execution of the pilot test.

The pilot testing will take place on 2 levels:

- Transational learning activity in which the participating teachers receive training on how to embed creativity techniques, into their teaching activities, share knowledge and gain insight into how to use the CHET tools for this.

- Pilot testing in which a selected sample of teachers will use the CHET learning environment and a specific set of them will implement a selected technique in a classroom.

Students will play an important role in the validation of the second level, as after the implementation of the selected technique they will assess the interest of this kind of educational innovation. 


\section{Expected results and impact}

CHET will already generate a turnaround in the perception of creativity and innovation in the higher educational system and by the teachers. CHET foresees a study and solid analysis to define the 'ideal' skillset for creativity and innovation in the teaching activities of HE STEM teachers, as well as the most pressing needs in terms of its implementation. The result is relevant not only for the present project, but for any activities in the field of educational innovation and creativity in other areas of study, as well as in other types of education.

CHET Erasmus + project will bringing together a comprehensive set of creativity and innovation techniques, specifically for the HE STEM areas, with guidelines, tip and tricks and examples/testimonies of their use in a real teaching activity. Teachers get easy access to very concrete skills, tools and embed creativity techniques and innovation in their teaching activities in practice.

Results and impact are aligned with these direct and indirect target groups:

- STEM HE teachers: focus on the need for acquiring skills and competences to integrate and embed creativity and innovation in teaching activities, and how the CHET outputs and results can help them to do so

- STEM HE institutions and their training bodies: to communicate the need for innovating in the teaching methods and integrate creativity and innovation skills into the educational curriculum (for teachers and students) and how CHET outputs and results will help them in this process.

- Policy makers and public authorities with competences in the field of education, to convey how CHET can help them to modernize the educational policies and system to the demands for of labour market and society and include creativity and innovation as an integral part of the education system and curriculum;

- Educational and/or creativity experts on the importance increased cooperation, and how CHET can provide guidance on how to change the educational environment and approaches

To ensure facilitate the uptake of the CHET outputs and results by the different target groups and stakeholders a set of guides and a policy brief are elaborated, which will describe the CHET e-learning platform, explain the benefits and provide examples of their implementation. 


\section{Conclusions}

Creativity and innovation are skills required by the labour market and a competitive economy, by embedding these type of techniques in the way subjects are taught and designed, will better prepare HE students for the challenges of both work as private life, and increasing labour market relevance of learning provision and qualifications.

Creativity must be understand how an horizontal skill in universitary studies, and it is a necessary abillity to apply others innovative education methodologies like Challenge and Project Based Learning, design thinking, collaborative learning, gamification, among others.

For this reason, it is necesary developing a new approach to embed creativity and innovation techniques and methodologies into HE teaching activities. It thus, introduces a set of skills which allow them to deliver high quality teaching in their subjects, and to address the need for educational approaches which are more adapted to the challenges and current demands.

CHET project promotes take-up of innovative practices in STEM HE by providing teachers with the skills and competence to support personalised learning approaches, collaborative learning and critical thinking. In this way, students can learn different subjects while using and achieving creativity skills.

\section{Acknowledgements}

The authors are grateful to Universidad Politécnica de Madrid funding for innovative education projects (2016-2020) and CHET Project is co-funded by the Erasmus+ Programme of the European Union (2019-2021)

\section{References}

Bocconi, S., Kampylis, P, Punie, Y. \& Farrer, P. (2012). Innovating Learning: Key Elements for Developing Creative Classrooms in Europe. Luxemburg: Joint Research Centre, Institute for Prospective Technological Studies. doi: 10.2791/90566

Csikszentmihalyi, M., \& Wolfe, R. (2014) New Conceptions and Research Approaches to Creativity: Implications of a Systems Perspective for Creativity in Education. In: The Systems Model of Creativity. Dordrecht: Springer

De Bono, E. (1970). Lateral thinking. A textbook of Creativity. London. Pelican Books.

European University Association, EUA. (2007). Creativity in Higher Education. Report on the EUA Creativity Project 2006-2007. Brussels: EUA. Retrieved from https://eua.eu/resources/publications/653:creativity-in-higher-education.html

Randstad. (2016). Annual Report. New conections. Amsterdam: Randstad Holding nv. Retrieved from https://www.randstad.com/investor-relations/results-andreports/randstad-annual-report-archive/randstad-annual-report-2016.pdf 
Rodríguez-Chueca, J., Molina-García, A., García-Aranda, C., Pérez, J., \& Rodríguez, E. (2019). Understanding sustainability and the circular economy through flipped classroom and challenge-based learning: an innovative experience in engineering education in Spain. Environmental Education Research. doi:10.1080/13504622.2019.1705965

Shernoff, D.J., Sinha, S., Bressler, D.M. \& Ginsburg, L. (2017). Assessing teacher education and professional development needs for the implementation of integrated approaches to STEM education. International Journal of STEM Education, 4(13). doi:10.1186/s40594017-0068-1 